\title{
The repassivation response from single cycle anodic polarization: The case study of a sensitized Al-Mg alloy
}

\author{
Monica Trueba*, Stefano P. Trasatti \\ Department of Chemistry, Università degli Studi di Milano, Via Golgi 19, Milan 20133, Italy
}

\section{A R T I C L E IN F O}

Article history:

Received 10 May 2017

Received in revised form 30 October 2017

Accepted 31 October 2017

Available online $\mathrm{xxx}$

\section{Keywords:}

Cyclic polarization

Repassivation

Al-Mg alloys

Sensitization

\begin{abstract}
A B S T R A C T
The repassivation behaviour of artificially aged 5083-H111 Al-Mg alloy in near neutral $\mathrm{NaCl}$ solutions was investigated by means of single cycle anodic polarization. Artificial aging was carried out at $150{ }^{\circ} \mathrm{C}$ during different times up to $360 \mathrm{~h}$. The characterization of the microstructure and composition by XRD, SEM/EDS and metallographic analyses indicated most favoured grain-boundary $\beta\left(\mathrm{Al}_{3} \mathrm{Mg}_{2}\right)$ phase precipitation for $168 \mathrm{~h}$ of isothermal treatment time. Nitric acid mass loss test (NAMLT) and microhardness measurements indicated the highest degree of sensitization (DoS) and developed strength for $168 \mathrm{~h}$ as well. For all the aging conditions, the potential drop at high currents during the reverse scan of the cyclic polarization was detected at the pit transition potential $\mathrm{E}_{\mathrm{ptp}}$ with similar but higher values than the corrosion potential of $\beta$ phase $\left(\mathrm{E}_{\mathrm{corr}} \approx-900 \mathrm{mV}\right.$ vs SCE). The associated current density $i_{\text {ptp }}$ and the steepness of the potential drop increase as the amount and contiguity of $\beta$ phase precipitates along grain boundaries. The onset and sustenance of metastable conditions that limit the simultaneous repassivation of all the corroded surfaces are driven by the anodic dissolution of $\beta\left(\mathrm{Al}_{3} \mathrm{Mg}_{2}\right)$. Metastable processes that limit the hydration of metal ions while producing high local hydrogen concentration are more likely to involve the formation/decomposition of reactive hydride intermediates. $\mathrm{E}_{\mathrm{ptp}}$ corresponds to the mixed electrode potential at which both metal dissolution and hydrogen evolution occur beyond some distance into the cavity, while $\mathrm{i}_{\mathrm{ptp}}$ evaluates the catalytic activity of the corroding surfaces. The effective anodic charge transfer coefficient $\alpha_{\text {eff }}$ determined from the steepness of the potential drop estimates the contribution of $\mathrm{Cl}^{-}$electromigration in response to local electrodissolution processes.
\end{abstract}

\section{Introduction}

Single cycle anodic polarization has been widely used for investigating the repassivation behaviour of $\mathrm{Al}$ and alloys in chloride containing solutions [1-17]. A potential drop at high currents during the potential scan into the negative direction has been frequently detected [1-4,6-10,12-17]. This characteristic, illustrated for an Al-Mg-Si alloy in Fig. 1 [10], manifests a transition to more occluded local processes that limit the simultaneous repassivation of all the corroded surfaces $[1,8]$. The transition supported by the critical pit chemistry has been recognized [1-10]. The potential at the inflection (Fig. 1), designated as the pit transition potential $\mathrm{E}_{\text {ptp }}$ according to Yasuda et al. [2], corresponds to the thermodynamic driving force of Al dissolution on freshly created (filmed) surface rather than on initially passive surface as for the pitting potential $\mathrm{E}_{\mathrm{pit}}[3,10]$. The associated current density $i_{\text {ptp }}$ is proportional to the rate at which hydrolysis equilibrium is reached at a critical saturation concentration of $\mathrm{Al}^{3+}[10]$, being represented by the following general equation to account for the con-

\footnotetext{
* Corresponding author.

Email address: monica.trueba@unimi.it (M. Trueba)
}

tribution of $\mathrm{OH}^{-}(\mathrm{pH}>7)$ :

$$
2 \mathrm{Al}^{3+}+\mathrm{H}_{2} \mathrm{O}+\mathrm{OH}^{-} \leftrightarrow 2 \mathrm{Al}(\mathrm{OH})^{2+}+\mathrm{H}^{+}
$$

Both $E_{p t p}$ and $i_{p t p}$ define the onset of metastable conditions that hinder the repassivation processes. The steepness or gradient of the potential decrease with current density at $\mathrm{E}<\mathrm{E}_{\mathrm{ptp}}$ (Fig. 1) is proportional to the local acidity removal for full hydrolysis to be reached at the protection potential $\mathrm{E}_{\text {prot }}[10]$.

The response to repassivation in aftermath of microstructural effects (e.g. impurities, precipitate phase, solute-depleted region) $[6,10,12]$ and of mechanical deformation (residual [13] and applied $[9,16,17]$ stresses) is not fully clear. The not distinguishable inflection detected for commercially pure Al 1050 exhibiting either etched or crystallographic pits [10] suggests that the presence of a salt layer in mass-transport limited repassivation is not mandatory. From studies with alloyed aluminium $[6,10], \mathrm{E}_{\mathrm{ptp}}$ does not change if the critical feature is the electrochemical behaviour of a precipitate phase, as for $\mathrm{Al}$ 6082-T6 which intergranular corrosion is governed by the selective dissolution of $\mathrm{Mg}_{2} \mathrm{Si}$ [10]. Conversely, $\mathrm{E}_{\mathrm{ptp}}$ varies if the critical feature is a solute depleted region as in the case of $\mathrm{Cu}$-containing alloys $[6,10]$. The shift of $E_{p t p}$ to less negative values with the amount of corrosion [10] is consistent with the selective dissolution of $\mathrm{Cu}$-rich particles producing less active $\mathrm{Cu}$-depleted zones between the 


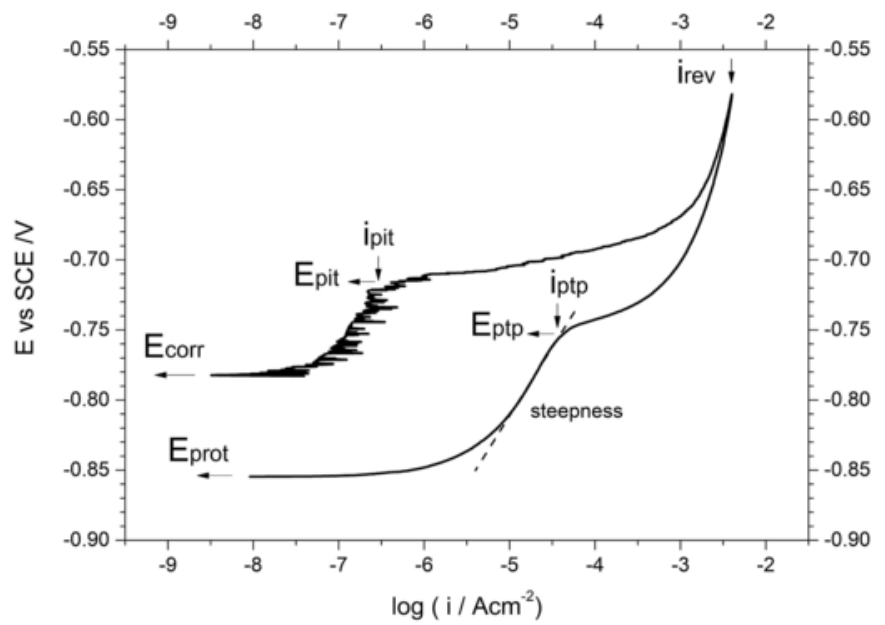

Fig. 1. Single cycle anodic polarization curve of $\mathrm{Al} 6082-\mathrm{T} 6$ in $0.6 \mathrm{M} \mathrm{NaCl}(\mathrm{pH} 6.5)$ [10], where $\mathrm{i}_{\text {rev }}$ represents the current density limit of the forward scan; $\mathrm{E}_{\text {corr }}$ - corrosion potential; $\mathrm{E}_{\text {pit }}$ and $\mathrm{i}_{\text {pit }}$ - pitting potential and the associated current density, $\mathrm{E}_{\mathrm{ptp}}$ and $\mathrm{i}_{\text {ptp }}$ - pit transition potential and the associated current density; $\mathrm{E}_{\text {prot }}-$ protection potential.

particles and the matrix [18]. Concerning the effect of mechanical stress on the response to repassivation, steeper potential gradients at the transition with accumulated strains by pressing have been reported for fine grained $\mathrm{Al}(99.9 \%)$ [9]. The opposite has been found for $\mathrm{Al}$ 2024-T3 subjected to residual elastic compressive stresses after removal of uniaxial tensile load [13]. A recent study with Al 2024-T3 and Al 7075-T6 under permanent load in bending has indicated that the effect of local stresses below the yield strength is enhanced with anodic processes localization during repassivation [17].

$\mathrm{Al}-\mathrm{Mg}$ alloys are of special interest from the prospective of the understanding and achievement of the balance between mechanical performance and corrosion resistance. It is well known that the susceptibility to intergranular corrosion (IGC) and intergranular stress corrosion (IGSC) increases with $\beta\left(\mathrm{Al}_{3} \mathrm{Mg}_{2}\right)$ phase precipitation along grain boundaries. This phenomenon, known as sensitization, becomes significant with long-time exposure at elevated temperatures $\left(50-200{ }^{\circ} \mathrm{C}\right)$. The nitric acid mass loss test (NAMLT) [19] is typically used for estimating the susceptibility to IGC in terms of the degree of sensitization (DoS) in $\mathrm{mg} / \mathrm{cm}^{2}$ of mass loss, being the traditional ranges of IGC susceptibility defined as: resistant (DoS $<15 \mathrm{mg}$ / $\left.\mathrm{cm}^{2}\right)$, intermediate $\left(15 \mathrm{mg} / \mathrm{cm}^{2}<\operatorname{DoS}<25 \mathrm{mg} / \mathrm{cm}^{2}\right)$ and susceptible $\left(\mathrm{DoS}>25 \mathrm{mg} / \mathrm{cm}^{2}\right)$. Because of the faster dissolution than the matrix of the $\beta$ phase in concentrated nitric acid, the mass loss increases due to grain fall-out with the amount and connectivity of $\beta$ phase at grain boundaries. The interdependence between the exposure conditions (temperature, time and environment) and interrelated variables such as metallurgical, electrochemical and stress states, have been underlined in recent reviews reporting most of the relevant works on this argument and new experimental findings [20-23]. The critical temperature range $100-200{ }^{\circ} \mathrm{C}\left(\mathrm{DoS}>25 \mathrm{mg} / \mathrm{cm}^{2}\right)$ is determined by the appreciable diffusion kinetics and volume fraction of $\beta$-phase [20]. However, long-time exposure at ambient temperatures promotes sensitization due to the high equilibrium $\beta$-phase volume fraction. $\mathrm{Nu}$ cleation and growth of $\beta$ phase at other lattice defects such as at the interface between the matrix and intragranular second-phase particles and at dislocations may occur $[20,21]$. The apparent $\beta$-phase continuity parameter, defined as the ratio between the average nearest neighbour distance (NDD) and the average diameter $(\bar{d})$ of $\beta$ phase at grain boundaries, has been indicated as more adequate than DoS for predicting IGSC susceptibility [21]. A key aspect concerns the rate-con- trolling processes of IGC and IGSC propagation along the grain boundary between the $\beta$ phase particles. The anodic dissolution of the $\beta$ phase aiding the sustenance of the acidified pit-like chemistry for grain boundary diffusion of hydrogen and embrittlement has been considered in the IGSC mechanism of Al-Mg alloys [21-23].

In this paper, the effect of $\beta\left(\mathrm{Al}_{3} \mathrm{Mg}_{2}\right)$ precipitation at grain boundaries on the repassivation behaviour of a high content of $\mathrm{Mg}(>4 \mathrm{wt} \%)$ $5083-\mathrm{H} 111 \mathrm{Al}$ alloy in $0.6 \mathrm{M} \mathrm{NaCl}(\mathrm{pH} 6.5)$ is investigated by means of single cycle anodic polarization. The alloy specimens were isothermally treated at $150{ }^{\circ} \mathrm{C}$ in air during different times and characterized by XRD, SEM/EDS and metallographic analyses. The DoS and the mechanical properties were evaluated by conventional NAMLT and microhardness measurements.

\section{Experimental part}

The starting material was a commercial wrought sheet (thickness $1.5 \mathrm{~mm}$ ) of 5083-H111 Al alloy with nominal composition (wt \%) $4.3 \mathrm{Mg}-0.6 \mathrm{Mn}-0.3 \mathrm{Fe}-0.2 \mathrm{Si}-$ bal. Al (Aviometal Spa., Italy), present in the laboratory since 2006 (aged $\approx 10$ years aged at room temperature). Metallic specimens of dimensions $20 \times 30 \mathrm{~mm}$ were wet ground up to 1200 grit using $\mathrm{SiC}$ papers, then polished with 4000 grit $(3 \mu \mathrm{m}) 3 \mathrm{M}$ polishing paper, and cleaned with ethanol in an ultrasonic bath. Thermal treatment was carried out at $150^{\circ} \mathrm{C}$ in an open to air oven during different times (from 24 to $360 \mathrm{~h}$ ). The composition and microstructure of the untreated and isothermally treated specimens were evaluated by XRD, SEM/EDS and metallographic analyses. The diffractograms were collected using Philiphs PW 1830 diffractometer with $\mathrm{CuK} \alpha$ radiation from 5 to $80^{\circ}$ of $2 \theta$. XRD data were analyzed with Diffrac plus EVA software (Master database, Bruker). SEM/EDS analysis of freshly-prepared specimens with surfaces polished up to $0.05 \mu \mathrm{m}$ grain size of colloidal alumina (water-based dispersion) was performed at LEO 1430 scanning electron microscope (SEM) equipped with EDS spectrometer at the chamber pressure of $8 \times 10^{-6}$ torr and $20 \mathrm{keV}$ accelerating voltage. Another set of specimens was used for metallographic analysis, following a reported procedure [24]. Briefly, the surfaces were chemically etched by immersion in $\left(\mathrm{NH}_{4}\right)_{2} \mathrm{~S}_{2} \mathrm{O}_{8}(10 \mathrm{~g} / 100 \mathrm{~mL})$ at room temperature during $30 \mathrm{~min}$ and thereafter examined at Nicon Eclipse MA200 metallographic microscope coupled with JCV-C1380 digital photocamera. Nitric acid mass loss test (NAMLT) was used to evaluate the susceptibility to IGC in terms of the degree of sensitization (DoS) as guided by ASTM G 67 standard practice [19]. The specimens were immersed in $\mathrm{HNO}_{3}$ (70\%) during $24 \mathrm{~h}$ at room temperature after desmuting by $1-\mathrm{min}$ immersion in $5 \% \mathrm{NaOH}$ solution at $80{ }^{\circ} \mathrm{C}$ and 30 -seconds immersion in $\mathrm{HNO}_{3}(70 \%)$ with intermediate water rinse steps and final air drying. The DoS as mass loss (in $\mathrm{mg} / \mathrm{cm}^{2}$ ) was quantified from two replications. Micro-hardness measurements were performed following the micro-indentation standard practice ISO 14577/DIN 50359, using $1 \mathrm{~N}$ (0.1 kgff) onto the surface. Average Vickers hardness (VH) was calculated from five indentations for each test condition.

Electrochemical experiments were conducted at room temperature in stagnant naturally aerated $0.6 \mathrm{M} \mathrm{NaCl}(>99 \%$, Aldrich) with $\mathrm{pH}=6.5( \pm 0.2)[10]$. The electrochemical system consisted in a single-compartment O-ring cell with the working electrode surface of $1 \mathrm{~cm}^{2}$ (positioned upward), a Pt spiral wire as counter-electrode, and a Haber-Luggin capillary reference probe with a saturated calomel electrode (SCE). The electrodes were connected to a PC-driven Gamry Reference 600 potentiostat. Single cycle anodic polarization curves were recorded at a scan rate of $10 \mathrm{mV} / \mathrm{min}(0.1667 \mathrm{mV} / \mathrm{s})$ from the open circuit potential after $10 \mathrm{~min}$ of conditioning in the test 
solution. The potential scan was reversed at the preselected current density limit of $2.5 \mathrm{~mA} / \mathrm{cm}^{2}$ (i $\mathrm{i}_{\text {rev }}$, Fig. 1) and terminated when the current became cathodic. The polarization curves were replicated at least twice for a given treatment condition. Representative specimens were cleaned with MilliQ water and ethanol in an ultrasonic bath, then sectioned, mounted in a cold-working resin, and finally polished up to $0.05 \mu \mathrm{m}$ grain size of colloidal alumina (water-based dispersion), for cross-section corrosion morphology analysis at SEM.

Graphical and quantitative analyses of the experimental data were carried out using OriginPro 2016 (OriginLab, Northampton, MA), as reported elsewhere [10].

\section{Results and discussion}

$\mathrm{XRD}, \mathrm{SEM} / \mathrm{EDS}$ and metallographic analyses of thermally treated Al 5083-H111 specimens indicated good agreement with reported microstructural changes of Al-Mg alloys due to sensitization [20]. The main secondary phases identified by XRD were $\mathrm{Mg}_{2} \mathrm{Si}, \mathrm{Al}_{6}(\mathrm{Fe}, \mathrm{Mn})$ and $\beta\left(\mathrm{Al}_{3} \mathrm{Mg}_{2}\right)$ (supplementary data, Fig. S1). The number of diffraction lines for the latter two phases was higher for $168 \mathrm{~h}$ of isothermal treatment at $150{ }^{\circ} \mathrm{C}$. For this treatment time, larger $\mathrm{Al}_{6}(\mathrm{Fe}, \mathrm{Mn})$ particles and less discontinuous precipitation of $\beta$ phase along grain boundaries were observed on the etched surfaces at the metallographic microscope (Fig. 2). Similarly, SEM/EDS analysis (Fig. 3) indicated more significant nucleation and growth of $\beta$ phase at the interface between $\mathrm{Al}$ matrix and either intragranular $\mathrm{Al}_{6}(\mathrm{Fe}, \mathrm{Mn})$ or $\mathrm{Mg}_{2} \mathrm{Si}$ particles. Accordingly, the isothermal treatment time of $168 \mathrm{~h}$ favours most the precipitation of $\beta\left(\mathrm{Al}_{3} \mathrm{Mg}_{2}\right)$ phase along grain boundaries and at other lattice defects. The dimensions of $\mathrm{Al}_{6}(\mathrm{Fe}, \mathrm{Mn})$ and

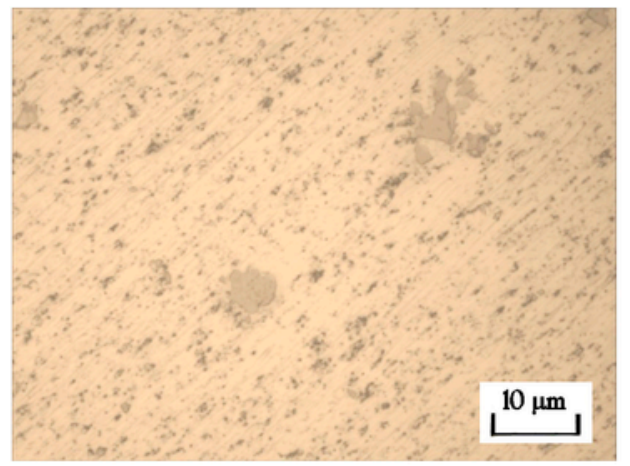

a

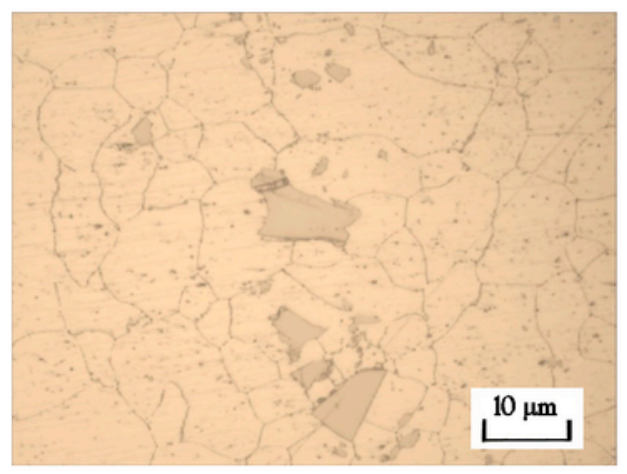

C
$\mathrm{Mg}_{2} \mathrm{Si}$ intermetallics decreased with prolonged thermal treatment (Fig. $\mathrm{S} 2$ ). In addition, the morphology of $\mathrm{Mg}_{2} \mathrm{Si}$ particles changed from roughly spherical to elongated shapes (Fig. 3b,d). Because of the reduced solubility of silicon in high $\mathrm{Mg}$ content $\mathrm{Al}$ alloys [25], unbalanced $\mathrm{Mg}_{2} \mathrm{Si}$ due to excess of $\mathrm{Si}$ was detected for all the treatment conditions. Long-time isothermal treatment is likely to bring about elongated grains of smaller size (Fig. 2), being not so well discerned due to the lessening of grain-boundary beta phase precipitates (Fig. $\mathrm{S} 1)$. The variation of the degree of sensitization (DoS) in terms of mass loss with the treatment time (Fig. 4) reproduces rather well documented data for as-solutionized Al 5083 (see Fig. 4 in Ref. [20]). The closely equal DoS values for the untreated alloy $(0 \mathrm{~h})$ and that reported for as-received $\mathrm{Al} 5083 \mathrm{H}\left(\approx 9 \mathrm{mg} / \mathrm{cm}^{2}\right)$ [23] suggest no significant effect of long-time aging under laboratory air environment on the susceptibility to IGC. The higher DoS for treatment times between 100 and $200 \mathrm{~h}$ (Fig. 4) correlates with the less discontinuous $\beta$ phase precipitation along grain boundaries (Fig. 2c). The mechanical properties of the alloy changed with the thermal treatment time also. The higher microhardness for sensitization times between 24 and $168 \mathrm{~h}$ (Fig. 5) suggests significant precipitation hardening [26]. By considering the DoS results (Fig. 4), the uniform distribution of fine $\beta$ phase particles in the case of $24 \mathrm{~h}$ of thermal treatment is likely to account for the strength development. The concomitant development of internal strains in the matrix [26] is expected to be significant for $100-200 \mathrm{~h}$ at $150^{\circ} \mathrm{C}$ because of $\beta$ phase precipitation at other than grain-boundary lattice defects (Fig. 3). For long-time exposure at $150{ }^{\circ} \mathrm{C}(\geq 240 \mathrm{~h})$, the decrease of both microhardness and DoS indicates reversion (or remediation) of sensitization at the expense of a loss in strength $[20,23]$, being consistent with the $\beta$ phase dissolution in the solid matrix (Figs. S1 and 2). The further relief of internal

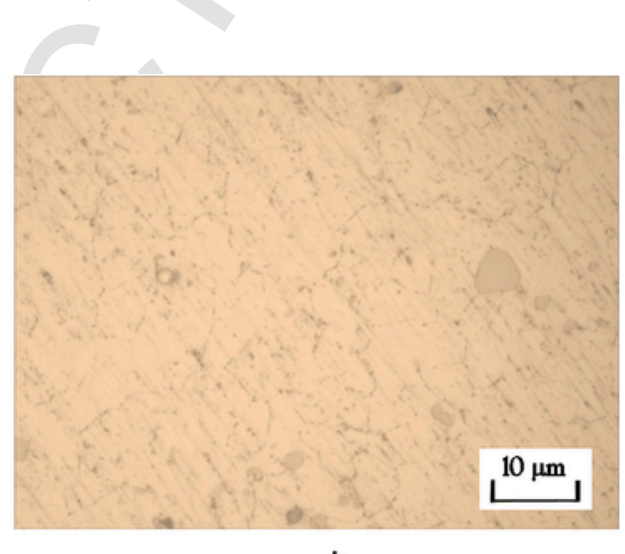

b

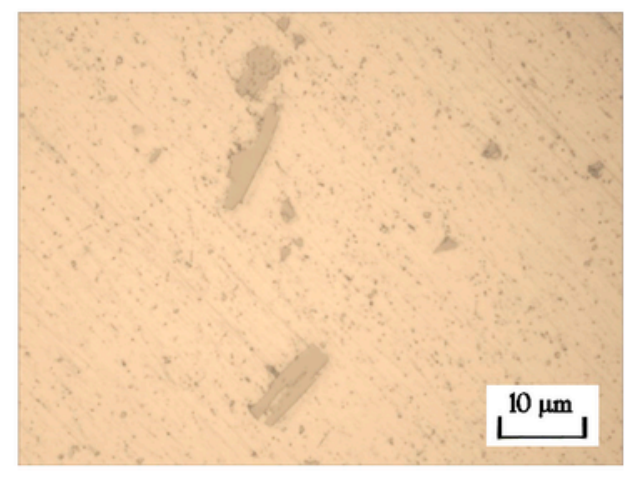

d

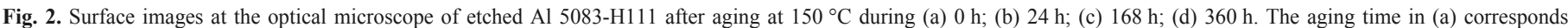

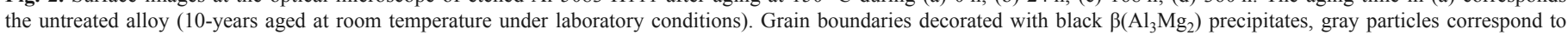
$\mathrm{Al}_{6}(\mathrm{Fe}, \mathrm{Mn})$. 


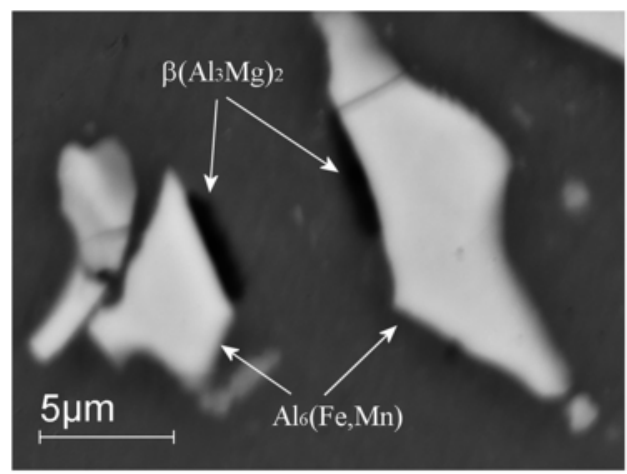

a

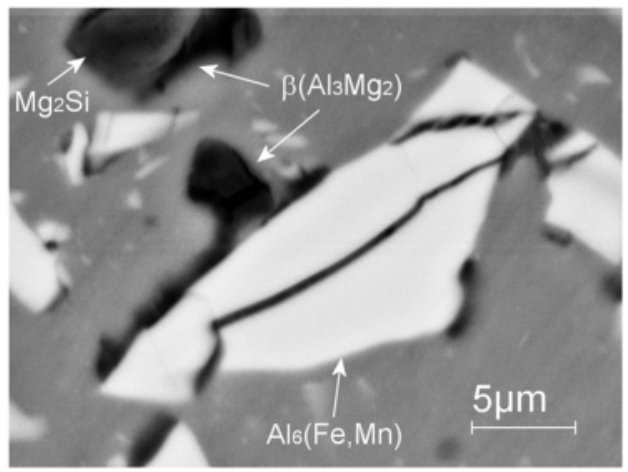

C

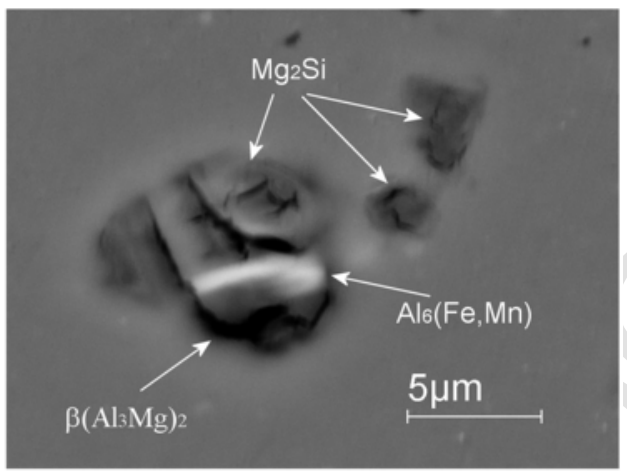

b

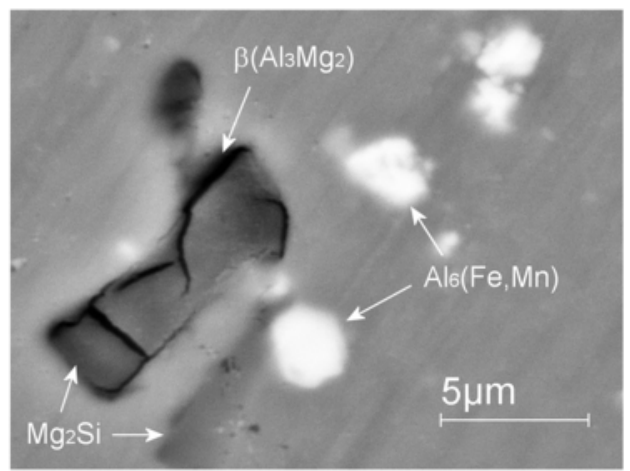

d

Fig. 3. Surface SEM/BSE images of as-polished Al 5083-H111 after isothermal treatment at $150{ }^{\circ} \mathrm{C}$ during (a,b) $24 \mathrm{~h}$; (c) $168 \mathrm{~h}$; (d) $360 \mathrm{~h}$.

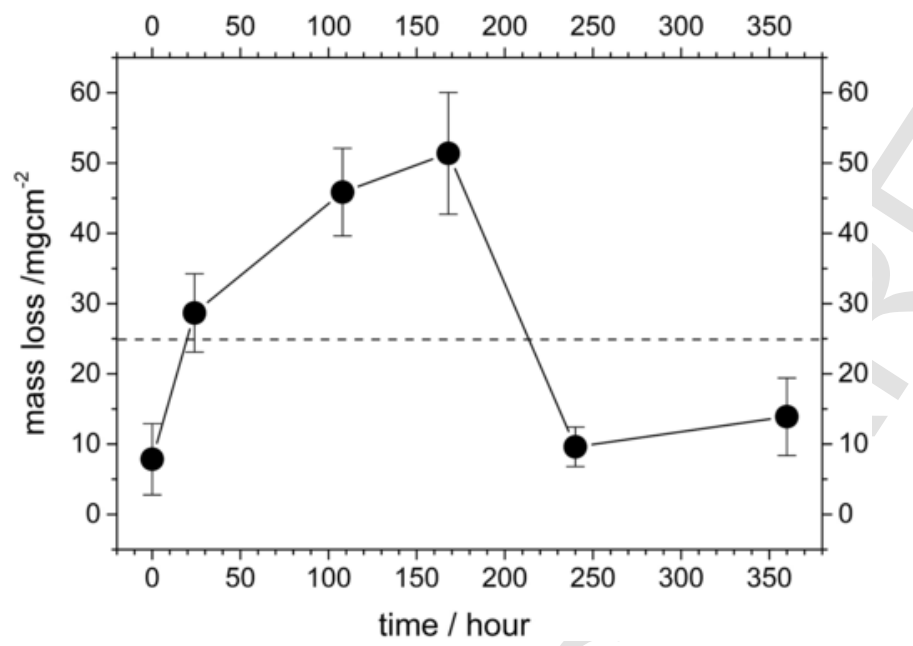

Fig. 4. Mass loss as a function of time at $150{ }^{\circ} \mathrm{C}$ for $\mathrm{Al} 5083-\mathrm{H} 111$. The time of $0 \mathrm{~h}$ corresponds to the untreated alloy. Error bars represent the standard deviation of the mean mass loss values. The dashed line correspond to $\operatorname{DoS}=25 \mathrm{mg} / \mathrm{cm}^{2}$.

stresses for $360 \mathrm{~h}$ (Fig. 5) could be ascribed to microstructural transformation altering the structure and the composition of the grain boundary $[20,26]$.

The electrochemical response to single cycle anodic polarization in $0.6 \mathrm{M} \mathrm{NaCl}(\mathrm{pH} 6.5)$ for the different aging conditions is summarized in Fig. 6. The average $\mathrm{E}-\log \mathrm{i}$ curves for a given sensitization treatment (Fig. 6a) were calculated from replicated experiments with the help of OriginPro built-in average multiple curves function. The error bars drawn for 40 averaged values of $\mathrm{E}$ for a given $\log \mathrm{i}$ illustrate the variability of replicated measurements of the cyclic curves.

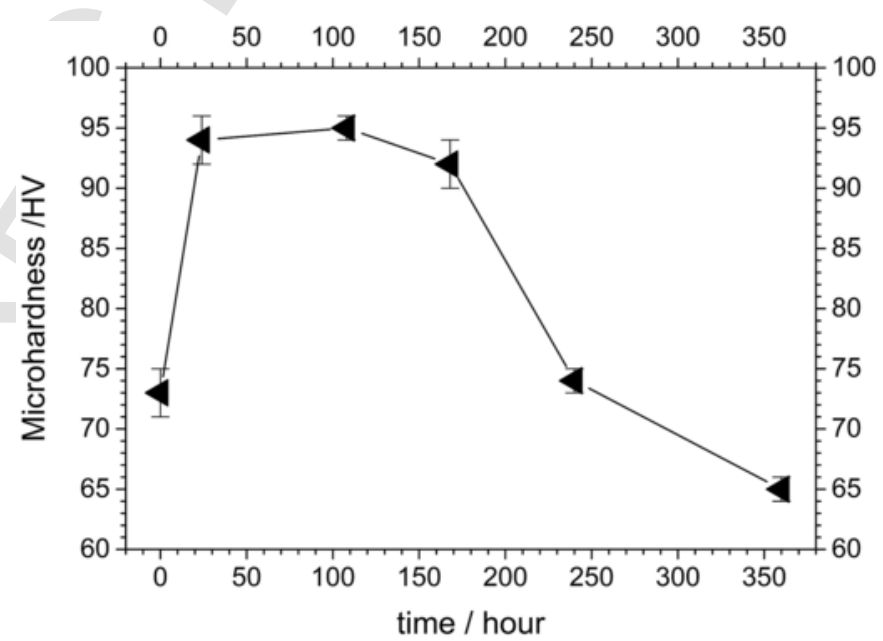

Fig. 5. Micro-hardness as a function of time at $150{ }^{\circ} \mathrm{C}$ for $\mathrm{Al} 5083-\mathrm{H} 111$. The time of $0 \mathrm{~h}$ corresponds to the untreated alloy. Error bars represent the standard deviation.

The response to the positive potential scan is featured by a significant increase of the current density at similar pitting potentials $\left(E_{\text {pit }}=-740 \pm 10 \mathrm{mV}\right.$ vs SCE$)$, regardless the extent of $\beta$ phase precipitation (Figs. 2 and 3). Likewise, the inflection during the potential scan into the negative direction is detected at closely equal pit transition potentials $\left(\mathrm{E}_{\mathrm{ptp}}=-775 \pm 5 \mathrm{mV}\right.$ vs $\mathrm{SCE}$ ). The corrosion potential of the $\beta$ phase in $0.6 \mathrm{M} \mathrm{NaCl}$ is more negative $\left(\mathrm{E}_{\mathrm{corr}} \approx-900 \mathrm{mV}\right.$ vs SCE) [21]). This phase can sustain high dissolution currents between $\mathrm{pH} 2-10$ [27], while $\mathrm{Al}(\mathrm{OH})_{3}$ is stable between $\mathrm{pH} 4-9$ and $\mathrm{Mg}(\mathrm{OH})_{2}$ at alkaline $\mathrm{pH}$ only. Accordingly, metastable processes that hinder the simultaneous repassivation of all the corroded surfaces are 


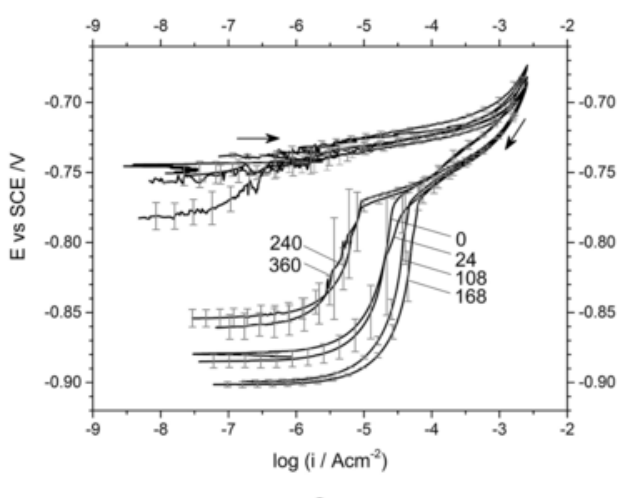

a

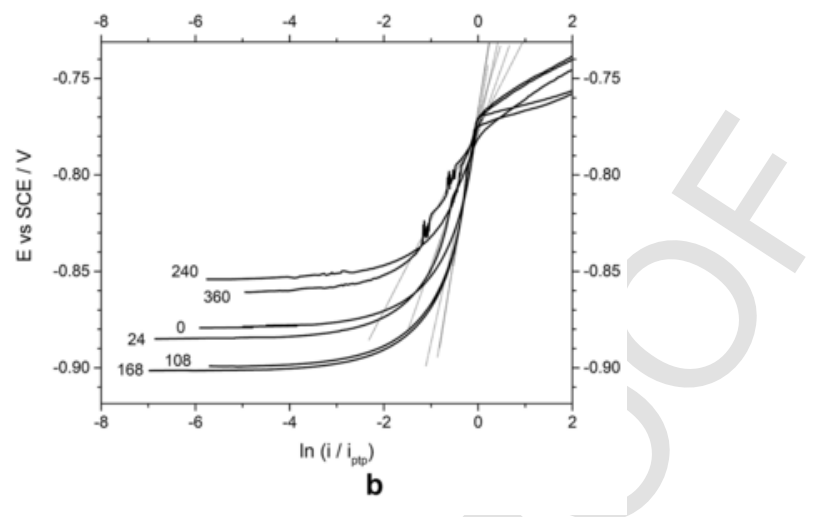

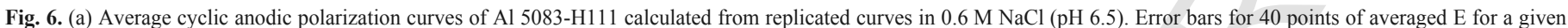

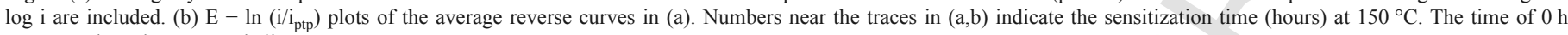
corresponds to the untreated alloy.

driven by the electrochemical activity of the $\beta$ phase. This fact supports further the close relation between $E_{\text {pit }}$ and $E_{p t p}$ [3], being the former potential less reproducible as influenced by the initial surface state condition [10]. The smaller by about $40 \mathrm{mV} \mathrm{E}_{\mathrm{ptp}}$ reproduces previous results with the untreated alloy [10] and is consistent with the thinner layer of the non-protective as-filmed surface during the first stages of repassivation.

Regardless the above, only the reverse curves change with the isothermal treatment time as the amount and contiguity of $\beta$ phase precipitation along grain boundaries. That is, by increasing the isothermal treatment time up to $168 \mathrm{~h}$, the inflection at $\mathrm{E}_{\mathrm{ptp}}$ shifts to higher current densities $i_{p t p}$ and the gradient or steepness of the potential drop increases with respect to the untreated alloy (Fig. 6a). The opposite trend is obtained for 240 and $360 \mathrm{~h}$. Thus, the protection potential $\mathrm{E}_{\text {prot }}$ changes non-monotonically between -850 and $-900 \mathrm{mV}$ (vs SCE), obtaining the more negative values for 100 and $200 \mathrm{~h}$ at $150{ }^{\circ} \mathrm{C}$ (Fig. 6). The variation of the steepness and of $\mathrm{E}_{\text {prot }}$ with the thermal treatment time are better discerned from the corresponding reverse curves plotted as $\mathrm{E}$ vs $\ln \left(\mathrm{i} / \mathrm{i}_{\mathrm{ptp}}\right)$ (Fig. 6b). The less negative ill-defined inflection at about $-0.74 \mathrm{~V}$ for 240 and $360 \mathrm{~h}$ (Fig. 6b) could be ascribed to the repassivation of superficial IG corroded sites due to surface spreading of $\beta$ phase attack [21]. The $E_{\text {prot }}$ values are closely similar to the $\mathrm{E}_{\text {corr }}$ of $\beta\left(\mathrm{Al}_{3} \mathrm{Mg}_{2}\right)$ phase in Al-Mg alloys: between -850 and $-900 \mathrm{mV}$ vs SCE for sensitized $\mathrm{Al} 5083-\mathrm{H} 131$ in $0.1 \mathrm{M} \mathrm{NaCl}(\mathrm{pH} 8)$ [21], as-received $\mathrm{Al} 5083-\mathrm{H} 131$ in $0.01 \mathrm{M} \mathrm{NaCl}$ (pH 4-8) [27], and sensitized Al-5 wt $\% \mathrm{Mg}$ microelectrodes in deaerated $0.6 \mathrm{M} \mathrm{NaCl}(\mathrm{pH} 3.5)$ [28]. Accordingly, metastable processes during repassivation are driven and sustained by the anodic dissolution of the $\beta$ phase.

The empirical relationships of $\mathrm{i}_{\mathrm{ptp}}$ and of the steepness as a function of time at $150{ }^{\circ} \mathrm{C}$ are reported in Fig. $7 \mathrm{a}$ and $\mathrm{b}$. The values of $\mathrm{i}_{\text {ptp }}$ and of the steepness do not significantly differ for long-time aging at room temperature and for $24 \mathrm{~h}$ at $150{ }^{\circ} \mathrm{C}$, in spite of the different microstructure (Fig. 2), DoS (Fig. 4) and microhardness (Fig. 5). For isothermal treatment times between 100 and $200 \mathrm{~h}$, higher $\mathrm{i}_{\text {ptp }}$ and steepness correlate with higher DoS $\left(\approx 50 \mathrm{mg} / \mathrm{cm}^{2}\right)$ and microhardness. For treatment conditions that favour the reversion of the sensitization $(\geq 240 \mathrm{~h}$ at $150{ }^{\circ} \mathrm{C}$ ), the DoS differs little from that of the untreated alloy (Fig. 4) but $i_{\text {ptp }}$ values are much smaller (Fig. 7a) while the decrease of the steepness follows closely that of the microhardness (Figs. 7b and 5). These results indicate that matrix dissolution nearby grain boundaries is as important as the extent and contiguity of $\beta$ phase at grain boundaries, in support to IGC/IGSC propagation between discrete $\beta$ phase particles as proposed by others [ [20,21] and refs. therein]. The localization of anodic processes during repassivation is enhanced with $\beta$ phase precipitation at lattice defects $[[17,20]$ and refs. therein]. SEM analysis results of cross-sectioned corroded specimens strengthens the considerations above. Prevalent IG attack at the base of crevice like pits was observed for long time aging at room temperature and for $24 \mathrm{~h}$ at $150^{\circ} \mathrm{C}$ (Fig. 8a). IGSC morphology manifested by IG attack over multiple grains was evident for 168 h (Fig. 8b). Exfoliation corrosion was the prevalent type of damage for prolonged artificial aging ( $\geq 240$ h) (Fig. 8c), being ascribed to the more directional microstructure (Fig. 2d) [21].
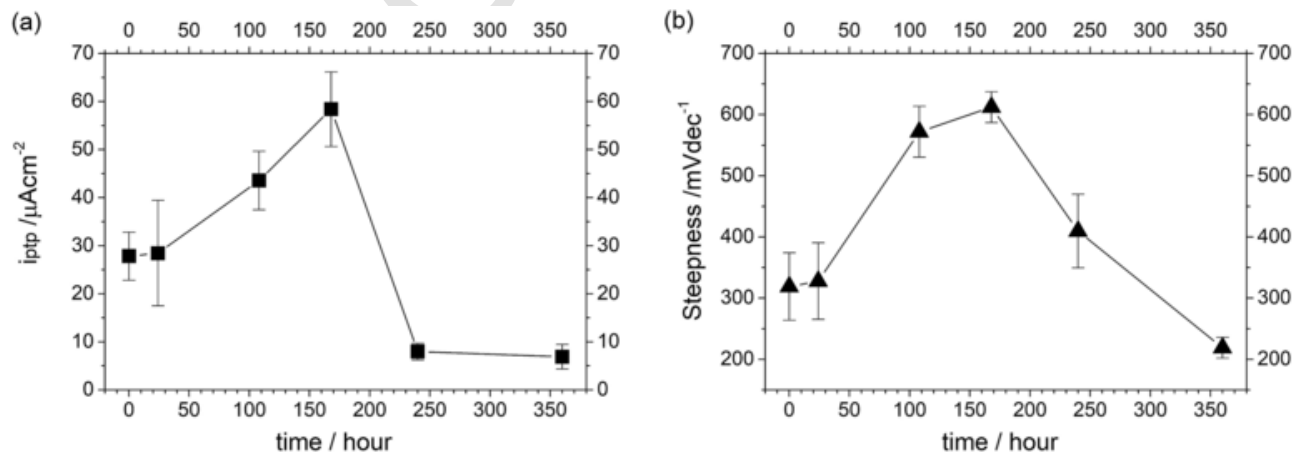

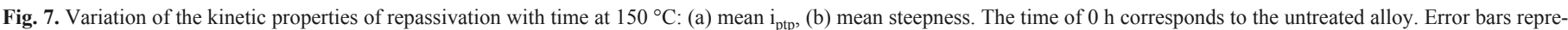
sent the standard deviation. 


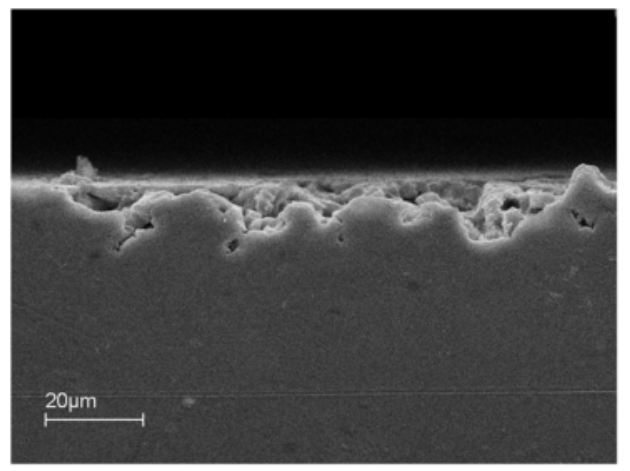

a

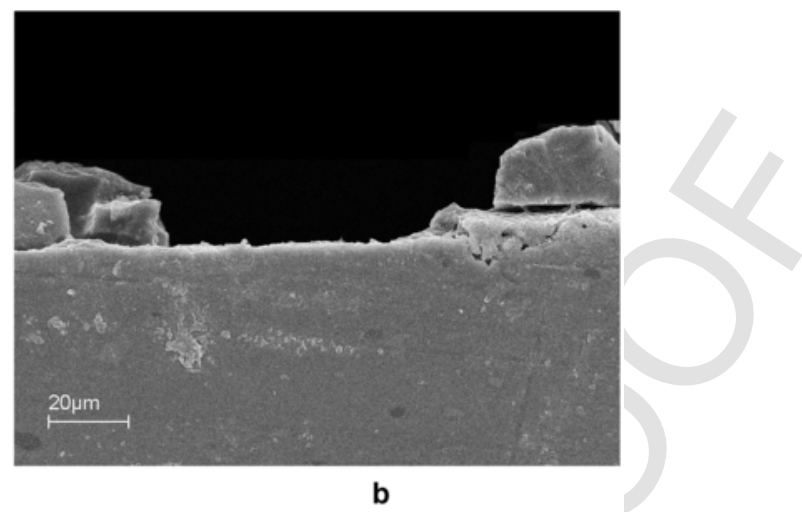

b

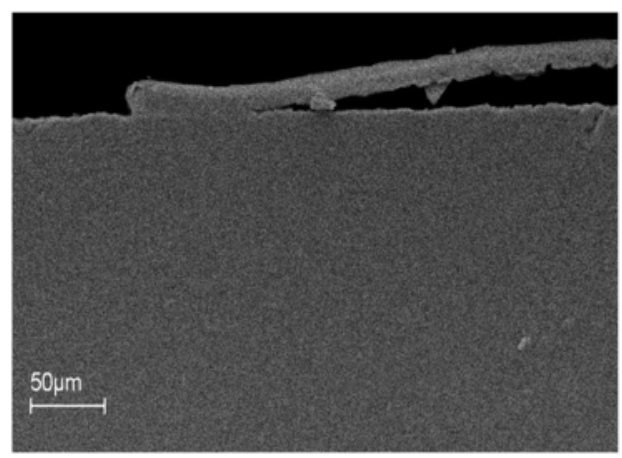

C

Fig. 8. Cross-section SEM images of corroded specimens that were submitted to 24,168 and $360 \mathrm{~h}$ of artificial aging at $150{ }^{\circ} \mathrm{C}$ prior the cyclic polarization (Fig. 6 ).

Summing up present findings, the susceptibility to IGSC due to sensitization can be evaluated from the repassivation response in near neutral $\mathrm{NaCl}$ solutions. Metastable processes that hinder the growth of protective corrosion products are driven and sustained by the anodic dissolution of $\beta\left(\mathrm{Al}_{3} \mathrm{Mg}_{2}\right)$ phase, being in accordance with its controlling role in the IGC and IGSC of Al-Mg alloys [20-23]. The $\mathrm{E}_{\mathrm{ptp}}>\mathrm{E}_{\text {prot }} \approx \mathrm{E}_{\text {corr }}$ of $\beta$ phase supports the prevalence of a simultaneous dissolution of both $\mathrm{Mg}$ and $\mathrm{Al}$ [29]. The resulting $\mathrm{Mg}^{2+}$ and $\mathrm{Al}^{3+}$ chloride complexes should promptly interact with water molecules to form densely hydrated oxychloride products [30,31]. The growth of a protective (hydr)oxide film should readily overcome that of the halide salt layer with decreasing potentials. Similarly, $\mathrm{H}^{+}$reduction at (hydr)oxide covered walls should assist the dilution of the local aggressive environment. The concentration gradients between the occluded cavity and the outer bulk solutions should easily decrease if the geometrical constriction of localized attack is not significant. This is likely the case of $168 \mathrm{~h}$ of isothermal treatment (Fig. 8b), being consistent with the highest $i_{\text {ptp }}$ (Fig. 7a) according to the reaction (1) and the highest DoS (Fig. 4), but not with the steeper potential drop at high currents (Figs. 6 and 7b). Accordingly, the anodic dissolution of $\beta$ phase drives and sustains electrodissolution processes nearby grain boundaries through a reaction pathway that limits $\mathrm{H}_{2} \mathrm{O} / \mathrm{OH}^{-}$adsorption and $\mathrm{H}^{+}$removal during repassivation. A self-driving process could be the anodic dissolution of the $\beta$ phase through hydrides intermediates that can actively deprotonate and thus be a source of hydrogen $[28,29] . \mathrm{E}_{\mathrm{ptp}}$ can be considered as the mixed electrode potential at which both metal dissolution and hydrogen evolution occur beyond some distance into the cavity, while $i_{\text {ptp }}$ reflects the catalytic activity of the corroding surfaces.

With the intention to supply a physical meaning to the steepness, high currents driving a potential drop during repassivation are related to mass transport processes involving metal electrodissolution and electromigration of $\mathrm{Cl}^{-}$through the highly conductive salt layer. The decrease of the potential below $\mathrm{E}_{\mathrm{ptp}}$ corresponds to the variation of the electrostatic potential at some distance into the cavities, being driven by a flow of charge across the metal/solution interface proportional to $\mathrm{i} \leq \mathrm{i}_{\text {ptp }}$. Assuming further that, for a stagnant electrolyte, the processes above depend only on the potential and their rate depends only on the concentrations of $\mathrm{Al}^{3+}$ and $\mathrm{Cl}^{-}$, the model developed by Engelhardt et al. [32] for calculating corrosion cavity propagation rates was used to estimate the effective anodic charge transfer coefficient $\alpha_{\text {eff }}$ from the steepness (Fig. 4b) with Equation (2):

$$
\ln \left(\frac{i}{i p t p}\right)=\frac{a_{e f f} F}{R T}\left(E-E_{p t p}\right)
$$

where $\mathrm{E}$ and $\mathrm{E}_{\mathrm{ptp}}$ are expressed in $\mathrm{V}$ (vs SCE), $\mathrm{F}=9.65 \times 10^{4} \mathrm{~J} / \mathrm{Vmol}$, $\mathrm{R}=8.31 \mathrm{~J} / \mathrm{molK}, \mathrm{T}=298 \mathrm{~K}$. Considering that $\alpha_{\mathrm{eff}}=\alpha-\lambda[32]$, where $\alpha$ is the anodic charge transfer coefficient and $\lambda$ the effective kinetic order of metal dissolution with respect to $\left[\mathrm{Cl}^{-}\right], \alpha_{\mathrm{eff}}$ allows to estimate the contribution of $\mathrm{Cl}^{-}$electromigration in response to local dissolution processes.

For all the investigated conditions, $\alpha_{\text {eff }}>0$ is consistent with the decrease of the dissolution rate as the potential shifts to more negative values (Fig. 6b). However, $\alpha_{\text {eff }}$ decreases from 0.35 to 0.17 with artificial aging up to $168 \mathrm{~h}$ and then increases to 0.54 for $360 \mathrm{~h}$. Accordingly, $\alpha_{\text {eff }} \rightarrow 0$ and $\alpha \rightarrow \lambda$ with $\beta$ phase precipitation indicates enhanced electromigration of $\mathrm{Cl}^{-}$for compensation of the potential drop while the dissolution rate tends to change less with the cavity length. The potential drop at high currents during repassivation is, all in all, a 
manifestation of the limited growth of the (hydr)oxide film over that of the salt layer.

Although it is not possible with the present data to propose a definite mechanism by which the aggressive local environment is sustained, some observations regarding the $\beta$ phase acting as local anode and as local source of hydrogen are disclosed. The generation of low $\mathrm{pH}$ is not sustained by the hydrolysis of non-acidic $\mathrm{Mg}^{2+}(\mathrm{pKa}=11.4)$ [31]. Complexes of $\mathrm{MgH}$ and $\mathrm{MgH}_{2}$ accounting for hydrogen embrittlement have been claimed because of the increased affinity between $\mathrm{Mg}$ and $\mathrm{H}$ in aluminium [21]. However, these hydrides would prevent further hydrogen diffusion and may readily hydrolyse as well $[29,33,34]$. Taking into account the predilection of $\mathrm{Mg}$ surface to reactively dissociate water and the low barrier of hydrogen atoms recombination on a defective $\mathrm{MgO}$ surface [31,35], as well as our recent experimental findings on hydrogen evolution during the anodic dissolution of Mg-Al alloys [36], oxidic hydrides could form according to the reaction (2):

$$
\mathrm{Mg}+\mathrm{H}_{2} \mathrm{O} \rightarrow\left\{\mathrm{Mg}^{2+} \mathrm{H}^{-}-\mathrm{O}^{2}-\mathrm{H}^{+}\right\} \rightarrow \mathrm{MgO}+\mathrm{H}_{2} \uparrow
$$

The "solvated" hydrides may react with $\mathrm{AlCl}_{3}$ to form metastable complex H-bridged networks of magnesium aluminohydrides (or alanates) of unit formula $\mathrm{Mg}\left(\mathrm{AlH}_{4}\right)_{2}$ [37,38]. Although this awaits verification through accurate studies, experimental evidence of magnesium alanate intermediates has been provided for $\mathrm{Mg}$-Al alloys [36]. In addition, $\operatorname{Mg}\left(\mathrm{AlH}_{4}\right)_{2}$ is less stable at ambient temperatures, exhibits higher gravimetric hydrogen density and presents a more open structure for hydrogen mobility in comparison to $\mathrm{MgH}_{2}$ [38]. Furthermore, the decomposition of $\mathrm{Mg}\left(\mathrm{AlH}_{4}\right)_{2}$ gives a stable mixture of $\mathrm{MgH}_{2}$ and $\mathrm{Al}$, alongside with $\mathrm{H}_{2}$ evolution, being the former sub-products experimentally detected during corrosion of $\mathrm{Al}_{3} \mathrm{Mg}_{2}$ [29]. The anodic dissolution of $\beta$ phase through reactive hydride intermediates like magnesium alanates would support the limited hydration of both $\mathrm{Al}^{3+}$ and $\mathrm{Mg}^{2+}$, the critical saturation concentration of $\mathrm{Al}^{3+}$ for production of fresh reactive surfaces nearby grain boundaries, and the build-up of high local concentration of hydrogen. The local generation of diffusible hydrogen species would assist the embrittlement and cracking between discrete $\beta$ phase precipitates at grain boundaries.

\section{Conclusions}

The effect of the isothermal sensitization at $150{ }^{\circ} \mathrm{C}$ on the susceptibility to IGC and IGSC of Mg-rich 5083-H111 Al alloy in near neutral $\mathrm{NaCl}$ is discerned from the repassivation response of single cycle anodic polarization. The analysis of the electrochemical potentials provided confirmation of the electrochemical behaviour of $\beta\left(\mathrm{Al}_{3} \mathrm{Mg}_{2}\right)$ phase as the critical feature in IGC/IGSC phenomena of Al-Mg alloys. The onset and sustenance of metastable conditions that hinder the simultaneous repassivation of all the corroded surfaces are enhanced with the amount and connectivity of $\beta$ phase at grain boundaries, in correlation with the increase of IGC/IGSC susceptibility in terms of DoS (NAMLT). The anodic dissolution of $\beta$ phase drives and sustains matrix dissolution nearby and along grain boundaries. The most likely metastable processes are related to the formation/decomposition of hydride intermediates that limit the growth of protective corrosion products while supply high local hydrogen concentration. $\mathrm{E}_{\mathrm{ptp}}$ is proposed as the mixed electrode potential at which both metal dissolution and hydrogen evolution occur beyond some distance into the cavity. The catalytic activity of the corroding surfaces is evaluated from $i_{\text {ptp }}$. The potential drop at high currents is related to
$\mathrm{Cl}^{-}$electromigration in response to local electrodissolution processes. The contribution of anodic processes localization during repassivation can be estimated from the steepness through the effective anodic charge transfer coefficient $\alpha_{\text {eff }}$.

\section{Acknowledgments}

Financial support from the Office of Naval Research under the contract number N62909-14-1-N217 with Dr. W. Nickerson as Scientific Officer is gratefully acknowledged. The views and conclusions contained herein are those of the authors and should not be interpreted as necessarily representing the official policies or endorsements, either expressed or implied, of the Office of Naval Research, the U.S. Navy or the U.S. government.

\section{Appendix A. Supplementary data}

Supplementary data related to this article can be found at https:// doi.org/10.1016/j.electacta.2017.10.202.

\section{References}

[1] K. Nisancioglu, H. Holtan, The protection potential of aluminum, Corros. Sci. 18 (1978) 1011-1023.

[2] M. Yasuda, F. Weinberg, D. Tromans, Pitting corrosion of Al and Al-Cu single crystals, J. Electrochem. Soc. 137 (1990) 3708-3715.

[3] S.T. Pride, J.R. Scully, J.L. Hudson, Metastable pitting of aluminium and criteria for the transition to stable pit growth, J. Electrochem. Soc. 141 (1994) 3028-3040.

[4] H.J. Raetzer-Scheibe, C.D.S. Tuck, The polarisation and repassivation behaviour of the aluminium-zinc-magnesium-copper alloy 7010, Corros. Sci. 36 (1994) 941-956.

[5] G.S. Frankel, J.R. Scully, C.V. Jahnes, Repassivation of pits in aluminum thin films, J. Electrochem. Soc. 143 (1996) 1834-1840.

[6] F.D. Wall, G.E. Stoner, The evaluation of the critical electrochemical potentials influencing environmentally assisted cracking of Al-Li-Cu alloys in selected environments, Corros. Sci. 39 (1997) 835-853.

[7] W. Zhang, G.S. Frankel, Transitions between pitting and intergranular corrosion in AA2024, Electrochim. Acta 48 (2003) 1193-1210.

[8] K.L. Moore, J.M. Sykes, P.S. Grant, An electrochemical study of repassivation of aluminium alloys with SEM examination of the pit interiors using resin replicas, Corros. Sci. 50 (2008) 3233-3240.

[9] O. Jilani, N. Njah, P. Ponthiaux, Transition from intergranular to pitting corrosion in fine grained aluminum processed by equal channel angular pressing, Corros. Sci. 87 (2014) 259-264.

[10] M. Trueba, S.P. Trasatti, Electrochemical approach to repassivation kinetics of Al alloys: gaining insight into environmentally assisted cracking, Corros. Rev. 33 (2015) 373-393.

[11] Q. Meng, G.S. Frankel, Effect of Cu content on corrosion behavior of 7xxx series alumnum alloys, J. Electrochem. Soc. 151 (2004) B271-B283.

[12] D.A. Little, B.J. Connolly, J.R. Scully, An electrochemical framework to explain the intergranular stress corrosion behavior in two $\mathrm{Al}-\mathrm{Cu}-\mathrm{Mg}$ - $\mathrm{Ag}$ alloys as a function of aging, Corros. Sci. 49 (2007) 347-372.

[13] X. Liu, G.S. Frankel, Effects of compressive stress on localized corrosion in AA2024-T3, Corros. Sci. 48 (2006) 3309-3329.

[14] Ch Mi, N. Lakhera, D.A. Kouris, D.A. Buttry, Repassivation behaviour of stressed aluminium electrodes in aqueous chloride solutions, Corros. Sci. 54 (2012) 10-16.

[15] U. Trdan, J. Grum, Evaluation of corrosion resistance of AA6082-T651 aluminium alloy after laser shock peening by means of cyclic polarisation and EIS methods, Corros. Sci. 59 (2012) 324-333.

[16] Y.C. Lin, G. Liu, M.-S. Chen, J.-L. Zhang, Z.-G. Chen, Y.-Q. Jiang, J. Li, Corrosion resistance of a two-stage stress-aged $\mathrm{Al}-\mathrm{Cu}-\mathrm{Mg}$ alloy: effects of external stress, J. Alloys Compd. 661 (2016) 221-230.

[17] M. Ferri, M. Trueba, S.P. Trasatti, M. Cabrini, A. Lo Conte, Electrochemical investigation of corrosion and repassivation of structural aluminum alloys under permanent load in bending, Corros. Rev. (2017) https://doi.org/10.1515/ corrrev-2017-0068

[18] S.P. Knight, N. Birbilis, B.C. Muddle, A.R. Trueman, S.P. Lynch, Correlations between intergranular stress corrosion cracking, grain-boundary microchemistry, and grain-boundary electrochemistry for $\mathrm{Al}-\mathrm{Zn}-\mathrm{Mg}-\mathrm{Cu}$ alloy, Corros. Sci. 52 (2010) 4073-4080. 
[19] Standard Test Method for Determining the Susceptibility to Intergranular Corrosion of 5XXX Series Aluminum Alloys by Mass Loss after Exposure to Nitric Acid (NAMLT Test), ASTM International, West Conshohocken, PA, 2004.

[20] R. Zhang, S.P. Knight, R.L. Holtz, R. Goswami, C.H.J. Davies, N. Birbilis, A survey of sensitization in 5xxx series aluminum alloys, Corrosion 72 (2016) 144-159.

[21] M.L.C. Lim, R.G. Kelly, J.R. Scully, Overview of intergranular corrosion mechanisms, phenomenological observations, and modeling of AA5083, Corrosion 72 (2016) 198-220.

[22] C.B. Crane, R.G. Kelly, R.P. Gangloff, Crack chemistry control of intergranular stress corrosion cracking in sensitized Al-Mg, Corrosion 72 (2016) 242-263.

[23] M. Seifi, N.J.H. Holroyd, J.J. Lewandowski, Deformation rate and sensitization effects on environmentally assisted cracking of Al-Mg naval alloys, Corrosion 72 (2016) 264-283

[24] Y.-K. Yang, T. Allen, Direct visualization of $\beta$ phase causing intergranular forms of corrosion in Al-Mg alloys, Mater. Charact. 80 (2013) 76-85.

[25] L.F. Mondolfo, Aluminium Alloys: Structure and Properties, Butterworths \& Co. Ltd., London, 1976.

[26] J.W. Martin, in: Butterworth-Heinemann (Ed.), Precipitation Hardening, second ed., Reed educational and professional Ltd., London, 1998, ISBN 0-7506-3885-0.

[27] J.A. Lyndon, R.K. Gupta, M.A. Gibson, N. Birbilis, Electrochemical behaviour of the $\beta$-phase intermetallic $\left(\mathrm{Mg}_{2} \mathrm{Al}_{3}\right)$ as a function of $\mathrm{pH}$ as relevant to corrosion of aluminium-magnesium alloys, Corros. Sci. 70 (2013) 290-293.

[28] L. Guan, Y. Zhou, B. Zhang, J.Q. Wang, E.-H. Han, W. Ke, Influence of aging treatment on the pitting behavior associated with the dissolution of active nanoscale $\beta$-phase precipitates for an Al-Mg alloy, Corros. Sci. 103 (2016) 255-267.

[29] M. Liu, P. Schmutz, S. Zanna, A. Seyeux, H. Ardelean, G. Song, A. Atrens, P. Marcus, Electrochemical reactivity, surface composition and corrosion mechanisms of the complex metallic alloy $\mathrm{Al}_{3} \mathrm{Mg}_{2}$, Corros. Sci. 52 (2010) 562-578.
[30] I. Waluyo, C. Huang, D. Nordlund, U. Bergmann, T.M. Weiss, L.G.M. Pettersson, A. Nilsson, The structure of water in the hydration shell of cations from $\mathrm{x}$-ray Raman and small angle x-ray scattering measurements, J. Chem. Phys. 134 (2011), 0645131-10.

[31] G. Williams, H.N. McMurray, Localized corrosion of magnesium in chloride-containing electrolyte studied by a scanning vibrating electrode technique, J. Electrochem. Soc. 155 (2008) C340-C349.

[32] G. Engelhardt, M. Urquidi-Macdonald, D.D. Macdonald, A simplified method for estimating corrosion cavity growth rates, Corros. Sci. 38 (1996) 1613-1635.

[33] K. Zeng, T. Klassen, W. Oelerich, R. Bormann, Critical assessment and thermodynamic modeling of the Mg-H system, Int. J. Hydr. Energy 24 (1999) 989-1004.

[34] M. Palumbo, F.J. Torres, J.R. Ares, C. Pisani, J.F. Fernandez, M. Baricco, Thermodynamic and ab initio investigation of the $\mathrm{Al}-\mathrm{H}-\mathrm{Mg}$ system, Comput. Coupling Phase Diagrams Thermochem. 31 (2007) 457-467.

[35] C.D. Taylor, A first-principles surface reaction kinetic model for hydrogen evolution under cathodic and anodic conditions on magnesium, J. Electrochem. Soc. 163 (2016) C602-C608.

[36] D. Buggio, M. Trueba, S.P. Trasatti, Corrosion of Mg alloy in the presence of ammonium ion. Evidence of hydride sub-products, Corros. Sci. 104 (2016) 173-186.

[37] (a) M. Fichtner, O. Fuhr, Synthesis and structures of magnesium alanate and two solvent adducts, J. Alloys Compd. 345 (2002) 286-296; (b) M. Fichtner, J. Engel, O. Fuhr, A. Glöss, O. Rubner, R. Ahlrichs, The structure of magnesium alanate, Inorg. Chem. 42 (2003) 7060-7066.

[38] J. Graetz, New approaches to hydrogen storage, Chem. Soc. Rev. 38 (2009) 73-82. 